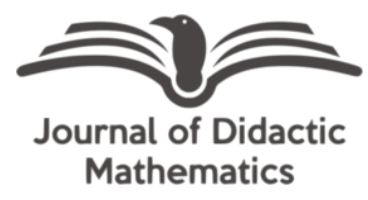

\title{
Teaching derivative concept using 6 questions cognitive model
}

\author{
Xiaofeng Lan \\ Guangxi Normal University
}

\section{Ying Zhou*}

Guangxi Normal University

*Corresponding Author: zhouying66@mailbox.gxnu.edu.cn

\begin{abstract}
Abstrak. Derivative is one of the basic concepts of calculus, has an extremely rich practical background and wide application. However, "low exploration" of the limit thought in teaching and learning activities have caused difficulties in future advanced mathematics learning. The purpose of this study is to create a learning model that helps students understand calculus. The method in this research is using research and development method, designing a learning model using 6 questions cognitive model on derivative material. Based on the results of developing a new learning model in this study using the six questions cognitive model to explore mathematics from the six dimensions of "from where", "what ", "why", "how", "what if it changed" and "think about it", The teaching and learning activities when teaching derivative under the cultural background reflects the continuity, naturalness and order of teaching. The results of this study indicate that 6 question cognitive models can help students learn the basic concept of calculus. The results of this study can be implemented by teachers in schools to improve the quality of high school student learning
\end{abstract}

Article History:

Received: October 1, 2020

Revised: October 22, 2020

Accepted: October 26, 2020

\section{Keywords:}

Research and development; Calculus; 6 questions cognitive model

Citation: Lan, X., \& Zhou, Y. (2020). Teaching derivative concept using 6 questions cognitive model. Journal of Didactic Mathematics, 1(3), 127-137. Doi: 10.34007/jdm.v1i3.371.

\section{INTRODUCTION}

In China, "student-oriented" as a basic concept is proposed in the new round of basic education curriculum teaching and learning (Yi, Ying, \& Wijaya, 2019). The student-oriented concept reflects the humanization of science and culture education (Lee \& Kim, 2017). Its important connotation is to integrate science and humanities into the cultural connotation of the curriculum (Aixia, Ying, \& Wijaya, 2020). Under the student-oriented concept, improving students' mathematical ability and cultural literacy has become the purpose of mathematics education. emphasizing the dialectical unity of mathematical literacy and humanistic literacy (Cunhua, Ying, Qunzhuang, \& Wijaya, 2019). Mathematics education is not only to impart mathematics knowledge and skills to students but also more importantly, to enable students to master mathematics thinking methods, comprehend the basic concept of mathematics (Dewi, Wijaya, Budianti, \& Rohaeti, 2018; Wijaya, Purnama, \& Tanuwijaya, 2020), understand the value of mathematics (Badraeni et al., 2020; Wijaya, Dewi, Fauziah, \& Afrilianto, 2018), and highlight the creative thinking ability of mathematics courses (Tan, Zou, Wijaya, Suci, \& Dewi, 2020). Therefore, integrating mathematics culture into mathematics education is not only a paradigm pursued by mathematics education research institutes at home and abroad but also an objective requirement and feasible way for mathematics curriculum reform in China (Qin, Zhou, \& Tanu, 2019).

Teaching is teaching students to think. Behind the knowledge and truth is the essence, ideology, continuity, and integrity of thinking (Duval, 2017). Its philosophical significance lies in 
the students' understanding of the reason why mathematicians can form such a way through mathematical knowledge and truth. The deep cultural existence of thought and creation (Sha, 2019). From the perspective of re-creation, students' mathematical ability and thinking process are the same as mathematicians' thinking, and the generation and development of mathematical knowledge and mathematical ideas are natural and reasonable. The basic unit of the modern curriculum is problem-based learning (Andini, Mulyani, Wijaya, \& Supriyati, 2018; Bernard, Sumarna, Rolina, \& Akbar, 2019; Hidayat \& Sariningsih, 2018). Therefore, based on the awareness of the problem, Professor Zhou Ying built a 6 question cognitive model that reflects the natural sequence, overall coherence and dynamic openness based on the awareness of the problems that exist in everyday life and from the perspective of teaching and learning (Figure 1). 6 questions cognitive model consists of 6 stages 1) from where 2) what 3) why 4) how 5) what if it changes 6) think about it (Lin, Zhou, Wang, \& Wijaya, 2020; Wijaya, Ying, Cunhua, \& Zulfah, 2020). Ask questions step by step on basic concepts, focusing on the cultivation of mathematical thinking ability.

Table 1. Step of 6 questions cognitive model

\begin{tabular}{|c|c|c|}
\hline Step & Six Cognitive question model & Explanation \\
\hline Step 1 & From where & $\begin{array}{l}\text { Where does this content come } \\
\text { from? }\end{array}$ \\
\hline Step 2 & What & What is this content? \\
\hline Step 3 & Why & $\begin{array}{l}\text { What is the connection } \\
\text { between this content and other } \\
\text { knowledge? }\end{array}$ \\
\hline Step 4 & How & How to learn this content? \\
\hline Step 5 & What if it changes & $\begin{array}{l}\text { Can we expand and improve } \\
\text { this content? }\end{array}$ \\
\hline Step 6 & Think about it & $\begin{array}{l}\text { How can students' } \\
\text { mathematical literacy improve? }\end{array}$ \\
\hline
\end{tabular}

The internal elements of the 6 questions cognitive model are interrelated and synergistic and are externally affected by students' conditions, teacher quality, and teaching environment. The application of this model provides a methodology for teachers to improve teaching and enhance the quality of thinking of teachers and help students to get deep learning. This study takes derivatives as an example to explore the teaching of 6 questions cognitive model.

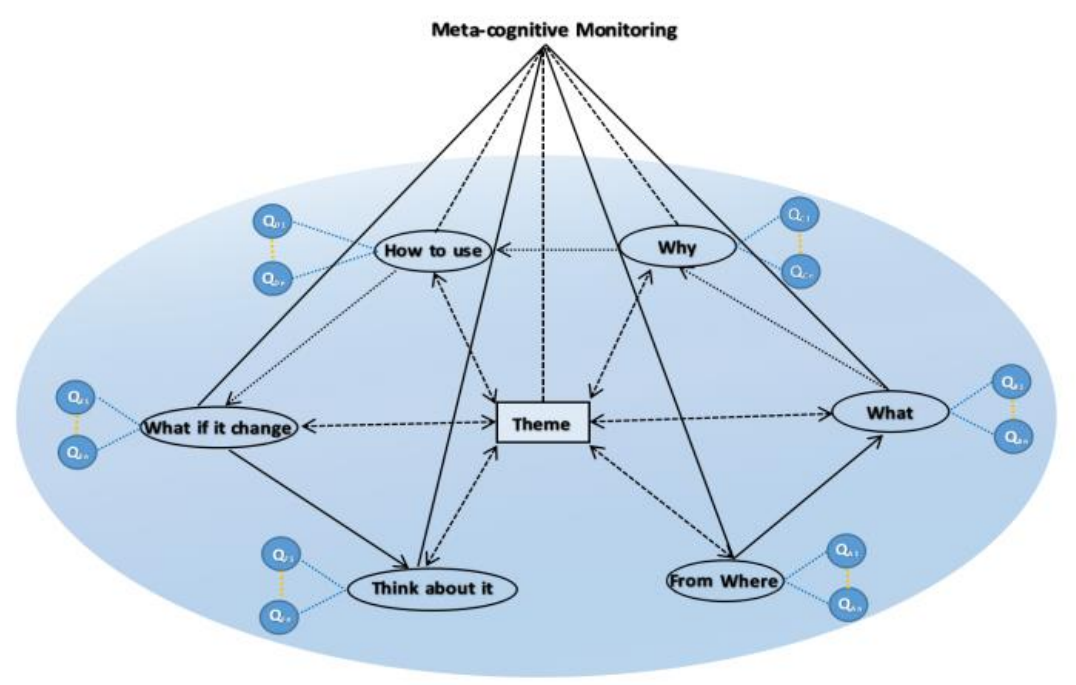

Figure 1. Six question cognitive model 
Calculus is one of the great achievements of human thinking. It opened a period of transition to modern mathematics and provided an important method for studying variables and functions. In terms of knowledge, the core concept of calculus is derivative, and the theoretical cornerstone is limit theory. In 1629, Fermat began to conceive the idea of derivative in the process of studying the tangent of the curve and the extreme value of the function (Biacino, 2014). In 1637, in order to solve the problem of making the tangent, Fermat constructed the difference $f(A+E)-f(A)$, which implies the concept of derivative (Verlag \& Leibnitiana, 2013). It was not until the $17^{\text {th }}$ century that the derivative formally entered the field of vision of humanity. The instantaneous velocity of Newton in physics created an infinitesimal amount. Leibniz used the definite integral problem to produce the concept of derivative in turn. In 1750 (Verlag \& Leibnitiana, 2013), D' Alembert used $\frac{d y}{d x}=\lim _{\Delta x \rightarrow 0} \frac{\Delta y}{\Delta x}$ to express the derivative; in 1823, Cauchy gave a strict definition of the derivative in the "Introduction to Infinitesimal Analysis" (Mathematica, 1978), in the 1860s, Weilstrass created the $\varepsilon-\delta$ language to reformulate the limit theory, perfect the theoretical basis of derivatives.

Closely related to the geometric meaning of derivatives is the tangent. Euclid believed that the tangent of a circle is a straight line that falls outside the circle and has only a common point with the circle. Apollonius and Archimedes also used the method of "there is only a common point with the curve and is located on one side of the curve" to define the tangent of the conic and spiral. In the $17^{\text {th }}$ century, mathematicians successively discovered and studied different methods of constructing the tangent of a general curve. It is generally believed that the tangent is the limit of the secant.

From the perspective of the basic concept development history of derivatives and tangents, these histories not only provide us with valuable materials but also provide a process of knowledge regeneration and development with cultural connotation and resonance, which opens up new horizons for teaching design.

Derivative teaching is an important part of high school mathematics teaching (Education, Fuentealba, \& Badillo, 2019). Limit thinking is the foundation of the concept of derivative. "infinitesimal" and "limit" are concepts that the ancient Greeks dared not touch, and they are also easily overlooked in teaching practice. Owing to the neglect of the limit thought, it will be difficult to learn advanced mathematics in the future. To understand the limit thought, we need to complete the leap from finite to infinite. The geometric meaning of derivatives is the lower level knowledge class of the concept of derivatives. Students master the upper level knowledgethe average rate of change, the instantaneous rate of change and the concept of derivatives, and further understand the meaning and value of derivatives from the perspective of geometric meaning, and experience the approximation, the mathematical thinking method of successive generation of music, combination of number and shape, and limit. At the same time, it also lays a solid foundation for the lower knowledge-the calculation of derivatives and the application of derivatives in research functions.

Analyze the students' academic situation from the perspective of knowledge reserve, students have learned the conic section and stayed on the concept of "the number of common points" and "whether the straight line is on the same side of the curve". So "the geometric meaning of derivatives" is taught let students realize that "whether the straight line is on the same side of the curve" is not the criterion for tangent lines, and stimulate students to learn new growth points. From the perspective of learning psychology, students have understood the derivative from the perspective of the "number" of practical meaning and numerical meaning. Students are also eager to understand the derivative from the perspective of geometric meaning, that is, the "shape", but students have individual thinking about the tangent. Set potential "the straight line with only one point in common with the curve and on one side of the curve is the tangent of the curve". Teachers need to create problem situations and use analogy methods to 
guide students to a level conceptually. The tangent of the general curve is defined by the approximation of the secant, to break through the teaching difficulty; "approach" idea.

Based on the problems of student difficulties described above, the purpose of this study is to explain how to teach calculus. The teaching method used to teach calculus is 6 question cognitive models. By explaining how to use the 6 question cognitive models here, it will be seen where the 6 question cognitive models can improve students' mathematical abilities and lead students to deep learning.

\section{METHOD}

This type of research is development research using instructional design to help students get deep learning. Derivatives material is the calculus content in senior high school student in China. Chapter 2 Derivatives and their applications in Chinese textbooks of the optional course. This class is the grade 10, senior high school and is taught to students in the second semester. Developing a learning plan using a six questions cognitive model. Steps 6 question cognitive model for teaching calculus in this study can be seen in Figure 2. The researcher simultaneously explains the important points in each phase of the 6 question cognitive model so that students can better understand the basic concepts of calculus material and get deep learning.
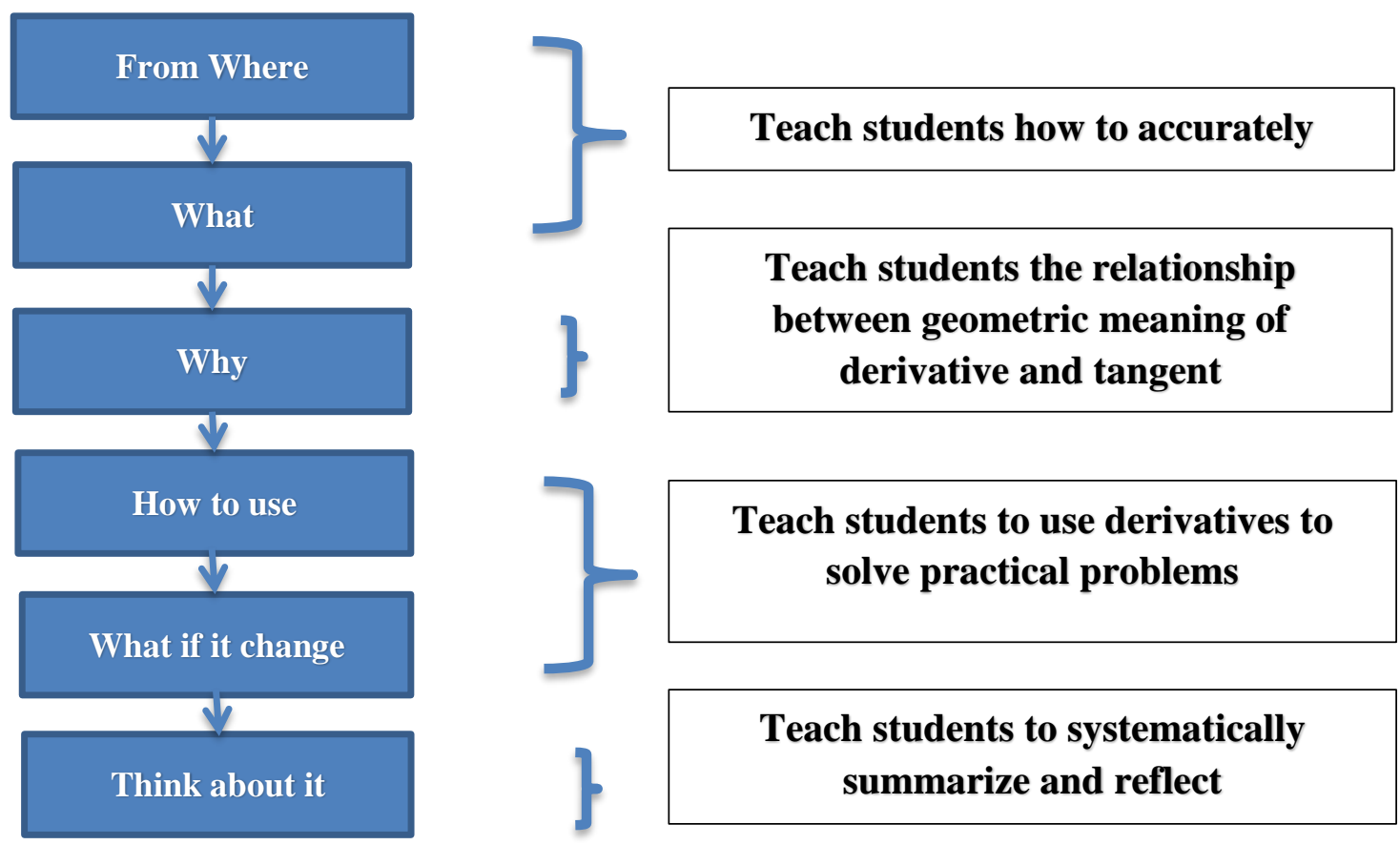

Figure 2. Six questions cognitive theory framework

\section{RESULTS AND DISCUSSION}

\section{"From where" stage}

"From where" stage emphasizing the creation of problem situations to everyday life. Introduce new knowledge, and a powerful answer to "why should you learn?" In the teaching process where "learning determines teaching" and "learning by teaching" complement each other, teachers and students are the cognitive subjects of teaching. Focusing on the knowledge of mathematics in the form of questions cannot only break the solidification or rigidity of teaching methods, but also It is beneficial to the reconstruction and innovation of mathematics teaching. In the specific teaching practice, the set of mathematics problems introduced in the classroom should conform to the students' cognitive law, combined with the connotative characteristics of the teaching content, and activate the growth point of new knowledge.

Question 1: We can draw the reflected light on a flat surface, so how is the light reflected 
Teaching derivative concept using...

on the curved surface?

Question 2: Knowing the trajectory of an object, how do we determine its speed direction?

Question 3: We have learned the slope of the slope, so how to determine the slope of the arch bridge?

"From where" as the beginning of the "six what" is the first link of classroom teaching, drawing on the three major problems of tangents studied by mathematicians in the 17 th centurythe reflection of light on curved surfaces, and the speed direction of curve movement The problem, the angle of the curve, design "reflection of light on the curved surface", "speed direction of the curve movement", and "slope of the arch bridge" 3 real-life problems to activate students' learning motivation and play Osubel The role of the "advanced organizer" and the promotion of learning are the "source" of new knowledge and new methods.

"what" stages

Mathematical concepts are the core of mathematical thinking methods, and the structure of mathematical knowledge is also developed around the core concepts. Ausubel believes that one of the prerequisites for meaning learning is to teach the concepts and principles that are inclusive, general and persuasive in the subject as much as possible. Bruner's educational principles on the basic structure of the subject emphasize that learning and mastering the concepts, definitions, principles and rules that are widely used in the subject is the best way to penetrate new knowledge fields. "What is it" means what the new knowledge is, focusing on answering "what is the nature and attributes of this mathematical object". It is not limited to the model of the concept itself but forms a hierarchical network with other mathematical objects. In teaching practice, teachers often directly tell students the concept of a certain mathematical object. What they teach is only a "noun". The memory of this "noun" may be lost in a long time. Therefore, the design is based on the nature and laws of knowledge. A string of essential questions, constructing core concepts, and commanding the entire teaching.

Question 1: In junior high school, how do we define the tangent and secant of a circle?

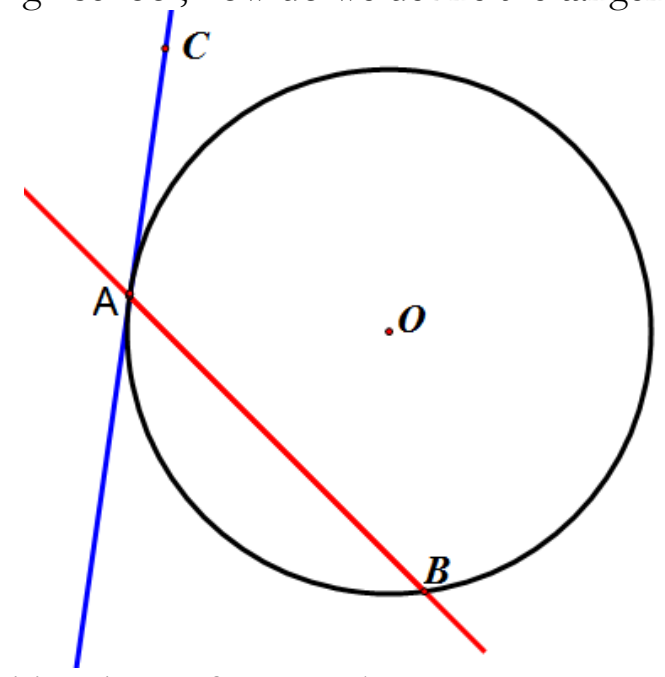

Figure 3. Six questions cognitive theory framework

Question 2: As shown in Figure 4, is it the tangent of the curve at point A?

Question 3: Is it the tangent of the curve at point B?

Question 4: Is it the tangent of the curve at point C? 


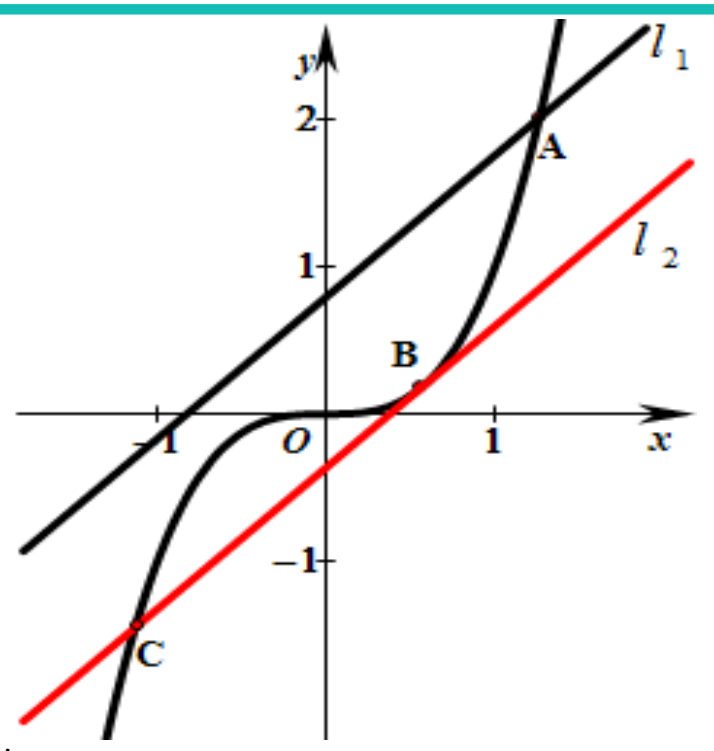

Figure 4. Curve $y=x^{3}$ and its tangent

Question 5: Can you compare the dynamic relationship between the tangent and the secant of a circle and find the tangent definition of a general curve?

Activity exploration: show Liu Hui's circular cutting technique (Figure 5), it can be obtained that the tangent of the circle is the line where the circle inscribes one side of the infinite polygon, and then the tangent of the circle is the limit position of the secant, and generalized to the general curve.

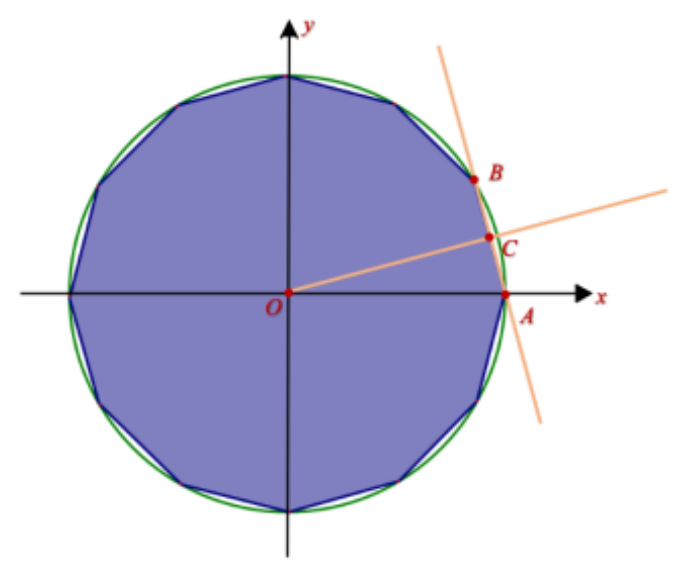

Figure 5. Circular cutting

Based on the principle of enlightenment and induction, ask questions in the "recent development zone" of students' thinking. Question 1 first aksed students' memories and then leads students to the scene of generating new knowledge with questions. The setting of questions 2 to 4 not only negates the promotion of "define tangents from the number of intersections and whether the straight line is on the same side of the curve", but also triggers students' cognitive conflicts, which greatly stimulates students' learning interest and desire to explore. On the basis of obtaining intuitive perception, students experience the occurrence and development of general curve tangents through the visual impact brought by the circle-cutting technique, realize the calculus thought of "replace music with straight lines", increase rational thinking, form tangent definitions, and deepen understanding of the definition of tangents, eliminating previous cognitive conflicts. 
Teaching derivative concept using...

"why" stage

The rise of the subject of mathematics is not due to a single reason, but the result of multiple reasons. Materialist dialectics believes that the whole governs the part and has functions that the part does not have. The holistic principle believes that there will be non-addictiveness between "partial" and "whole". There are many potential connections between mathematics objects and between mathematics and other disciplines, among which the problems of "partial" and "whole" are involved. Excavate the associations between various objects in teaching, guide students to make extensive associations, and shift from the mastery of a certain "partial" content to the construction of the "why" content of culture. "Why" stage solves the problem of "what is the connection", and points to how the new knowledge and the old knowledge, the elements within the knowledge, the elements and the overall structure are connected, and the design of a series of related problems not only enables students to learn "partial" knowledge but also "Overall" understanding of the knowledge and culture system.

Question 1: I have just intuitively perceived the change process of "secant approaching tangent". How to express this change in a quantitative relationship?

Question 2: As shown in Figure 5, given that, how to write the secant Pn equation?

Question 3: When the secant Pn passing through the fixed point P approaches the tangent, which part of the secant equation changes? What is the result of the change?

Question 4: How to write the tangent equation?

Question 5: What is the geometric meaning of the derivative?

Figure 6. Circular cutting

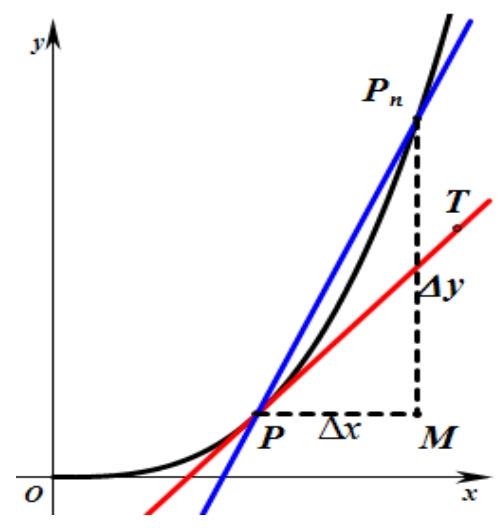

"why" stage aims to let students understand the connection between old and new knowledge and promote the integration of knowledge. Questions 1 to 5 inspire and guide students to think, let students experience the process of going from the known to the unknown, step by step, and explore the relationship between tangent and derivative. Point P Secant PPn Approaching the tangent, When the end result of the change is $\lim _{\Delta x \rightarrow 0} \frac{f\left(x_{0}+\Delta x\right)-f\left(x_{0}\right)}{\Delta x}=f^{\prime}\left(x_{0}\right)$, the tangent equation is $y-y_{0}=f^{\prime}\left(x_{0}\right)\left(x-x_{0}\right)$, according to the point oblique, the tangent passes through the point $\mathrm{P}, \lim _{\Delta x \rightarrow 0} \frac{f\left(x_{0}+\Delta x\right)-f\left(x_{0}\right)}{\Delta x}=f^{\prime}\left(x_{0}\right)$ is the slope of the tangent. Then it is concluded that the geometric meaning of the derivative is the slope of the tangent of the image of the function at. In this process, the derivative is used as the support and connection point, and the derivative is understood from the two aspects of numerical meaning and geometric meaning. Different aspects, focusing on the transformation between the two, further perfecting students" "holistic" cognition. 
"how" stage

"How" stage mainly detects how students have learned and the key to develop students' logical thinking. Teachers can understand students' knowledge and blind spots and misunderstandings in thinking from the perspective, method and process of students solving problems. Its basic task is to guide students to form a solid organic whole with knowledge, skills, ideas, and methods. Through the design and application of the problem string, it starts from a certain important mathematical knowledge, skill, and method to carry out a more in-depth analysis of its internal connections, focusing on testing whether students have formed and mastered important mathematical thinking methods and whether they can apply knowledge to solve problems. And then feedback the teaching effect.

Question 1: There is an elliptical surface. Can you draw the light reflected on the surface?

Question 2: The trajectory of an object thrown horizontally at a speed of $10 \mathrm{~m} / \mathrm{s}$ is 0 , what is the speed direction of the object at $(10,20)$ ?

Question 3: As shown in Figure 6, an arch bridge is to be built. It is required that the highest point of the arch bridge is $20 \mathrm{~m}$ away from the water surface, and the slope of the arch bridge cannot be greater than $30^{\circ}$. What is the span of the arch bridge?

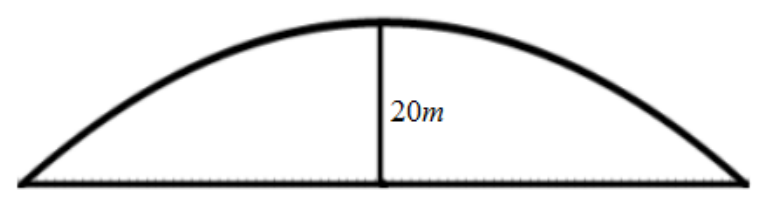

Figure 7. Circular cutting

After the previous study of from here stage, what stage and why stage, students have mastered the source of knowledge, essential characteristic values and related knowledge, but they still need to apply what they have learned to achieve the unity of knowledge and action. In this session, we take the three questions raised by "where" as an example to test how well students have learned and whether they can apply knowledge to solve problems and provide students with practice opportunities to answer the questions raised by "where" stage.

"what if it changes" stage

Mathematical thinking and mathematical methods cannot be accomplished only through "from where", "what is", "and what", and "how". They are spiralling upwards in repetition and must experience a step from shallow to deep, from simple to simple-the process of development from low-level to high-level. In addition, the continuity and systematicity of mathematical knowledge reveal the relevance and characteristics of knowledge. Teachers need to guide students to make horizontal and vertical comparisons and variant transfers of mathematical knowledge. The practice has proved that reasonable transformation of the nonessential characteristics of mathematical objects can promote students' in-depth understanding of them, and variant teaching has become a good carrier. Variation teaching is not a product of modern education, it can be traced back to the time when the book "Nine Chapters of Arithmetic" was written, and the variation thinking has expanded the connotation of educational-oriented mathematical culture research. "what if it changes" emphasizes variable expansion and abstract improvement, and the difficulty of the problem should be gradually increased. It guides students to re-examine the knowledge they have learned from different angles, promotes students' thinking divergence, and improves their ability to draw inferences from one another.

Question 1: If a beam of light passes through one focal point of an ellipse, after reflection, will the reflected light pass through another focal point?

Activity exploration: As shown in Figure 7, point A is the moving point on the ellipse, straight line 11 is the tangent of the ellipse at point $A, 12$ is the vertical line of $11, F_{1}$ and $F_{2}$ are the 
Teaching derivative concept using...

focal points of the ellipse, using the geometric sketchpad to measure $\angle F_{1} A B$ is it equal to $\angle \mathrm{F}_{2} \mathrm{AB}$, verify the optical properties of the ellipse.

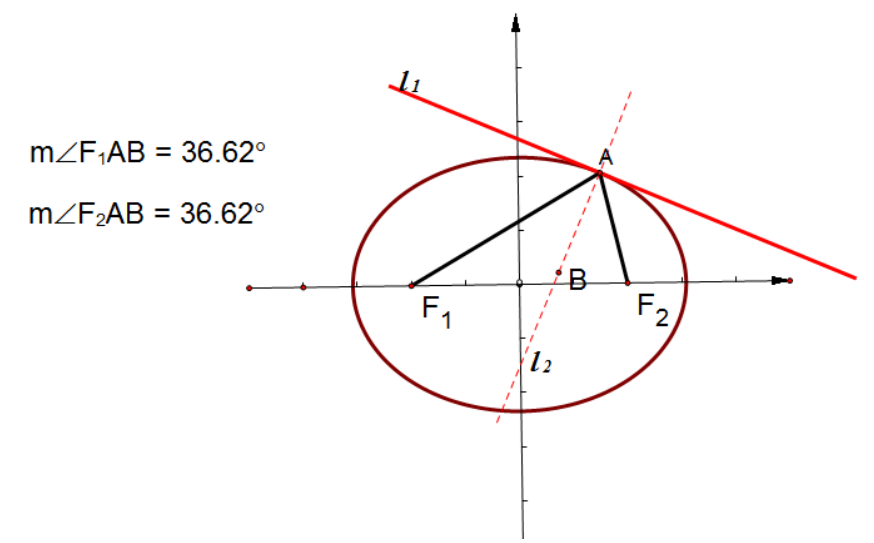

Figure 8. Verification of the optical properties of ellipses

Question 2: Can you use mathematical methods to prove the optical properties of ellipses?

The lecturer modified the problem of "reflection of light on curved surfaces", using the situation of light passing through the focal point of the ellipse to deepen students' understanding of the idea of "representing music with straight lines", linking physical knowledge, and helping students to understand in multiple directions know-how. The setting of Problem 2 is not only to solve mathematical problems but to guide students to explore the essence behind the phenomenon and broaden students' mathematics horizons.

"think about it" stage

After studying, students can conduct self-reflection, understand the educational value orientation of mathematics culture, understand the cultural importance of mathematics beyond scientism, and examine the scientific and humanistic attributes of mathematics, which will help to form a spirit of rational innovation. "What is there" to solve the problem of "what is there to reflect or new understanding", pay attention to where students grow up, what knowledge, ideas, methods, positive emotions they have learned, and where mathematics literacy has been improved, set up a series of reflection questions, one, on the one hand, teachers can obtain teaching feedback in multiple dimensions to create favourable conditions for subsequent teaching implementation. On the other hand, students can reflect on multiple perspectives and cultivate the habit of being good at the reflection, organize knowledge in a structured way, promote the development of metacognitive ability, and improve the thinking level.

Question 1: What problems can the geometric meaning of derivatives solve?

Question 2: In the process of studying the geometric meaning of derivatives, what mathematical ideas and methods are used?

Question 3: Can you summarize the learning of this section of derivatives in the form of a mind map?

Question 4: Is there any confusion or reflection?

Problem-oriented guide students to summarize and comb from the three aspects of knowledge, thinking, and methods (Rohaeti, 2010). Obtain some strategic knowledge and put forward their own puzzles based on what they have learned. student find knowledge blind spots and areas to be improved and re-read new knowledge understanding, optimizing their own knowledge structure, connecting points and networking, strengthening the awareness of selfevaluation, reflection and management.

learning 6 question cognitive model is in accordance with research that has been done before that by using 6 question cognitive models, students can better understand the basic concepts of mathematics, improve the quality of students' mathematical thinking (Wijaya, Ying, 
et al., 2020), direct students to get deep learning, improve student learning outcomes (Cunhua et al., 2019; Yi et al., 2019). Suggestions for teachers in schools to use 6 question cognitive models in every math lesson. The teachers can use 6 question cognitive models with the use of ICT. So that ICT can increase students' interest in learning. Further research, can examine the effect of 6 question cognitive models on students' mathematical abilities using the quantitave method.

\section{CONCLUSION}

As abstract subject with rich connotation, mathematics is widely influencing our daily life and thoughts of the public. Curriculum reform is entering the era of "basic concept literacy". Students are individuals with independent thoughts. Their emotions, attitudes, values, disciplinary literacy and key abilities should adapt to the current era. In the process of cultivating students' literacy, applying the 6 questions cognitive model to infiltrate mathematics culture into education and teaching in a problematic way, which can effectively cultivate students' higherorder thinking and reflection ability.

The 6 cognitive model on calculus always pays attention to the learning psychology of students, and guides students to construct new knowledge in an orderly and gradual manner; pays attention to the connection between knowledge, and creates situations to give students sufficient opportunities to associate and complete the knowledge system construct. At the same time, the knowledge of the history of mathematics is re-created. For example, in the introduction part, three types of questions about tangents researched by mathematicians in the 17th century are used to improve students' learning interest. In the concept construction part, the 6 cognitive model circle cutting technique is connected with the concept of tangents. Help students understand the basic concept of tangent and realize the inheritance and innovation of mathematical culture.

\section{ACKNOWLEDGEMENT}

We would like to thank to Guangxi Normal University for the research fund which has been given to the researcher. In 2019, Guangxi Higher Education Undergraduate Teaching Reform Project "research and practice of effective mathematics teaching guided by systematic thinking ability" (Project No: 2019JGZ110); in 2020, Guangxi Graduate Education Innovation Plan Project.

\section{REFERENCES}

Aixia, W., Ying, Z., \& Wijaya, T. T. (2020). The current situation and prospect of study quality evaluation research in china in the last 10 years. EDUKATIF: Jurnal Ilmu Pendidikan, 2(1), 101-112.

Andini, D., Mulyani, N., Wijaya, T., \& Supriyati, D. (2018). Meningkatkan Kemampuan Komunikasi Matematis Dan Self Confidence Siswa Menggunakan Pendekatan PBL Berbantuan Geogebra. Jurnal Derivat: Jurnal Matematika Dan Pendidikan Matematika, 5(1), 8293.

Badraeni, N., Pamungkas, R. A., Hidayat, W., Rohaeti, E. E., Wijaya, T. T., Sudirman, J. J., \& Barat, J. (2020). Analisis kesulitan siswa berdasarkan kemampuan pemahaman matematik dalam mengerjakan soal pada materi bangun ruang sisi datar. Jurnal Cendekia: Jurnal Pendidikan Matematika, 04(01), 247-253.

Bernard, M., Sumarna, A., Rolina, R., \& Akbar, P. (2019). Development of high school student work sheets using VBA for microsoft word trigonometry materials. Journal of Physics: Conference Series, 1315(1). https://doi.org/10.1088/1742-6596/1315/1/012031

Biacino, L. (2014). A Geometrical Solution by Fermat to a Problem of Maximum. Applied Mathematical Sciences, 8(136), 6827-6834.

Cunhua, L., Ying, Z., Qunzhuang, O., \& Wijaya, T. T. (2019). Mathematics course design based on six questions cognitive theory using hawgent dynamic mathematic. Journal On Education, 
Teaching derivative concept using... 02(01), 36-44.

Dewi, S. N., Wijaya, T. T., Budianti, A., \& Rohaeti, E. E. (2018). Pengaruh Model Teams Games Tournament Terhadap Kemampuan Pemahaman Matematik Siswa Kelas XI SMK di Kota Cimahi Pada Materi Fungsi Eksponen. WACANA AKADEMIKA: Majalah Ilmiah Kependidikan, 2(1), 99. https://doi.org/10.30738/wa.v2i1.2570

Duval, R. (2017). Understanding the mathematical way of thinking - The registers of semiotic representations. In Understanding the Mathematical Way of Thinking - The Registers of Semiotic Representations. https://doi.org/10.1007/978-3-319-56910-9

Education, T., Fuentealba, C., \& Badillo, E. (2019). The Understanding of the Derivative Concept in Higher Education 2 1. Eurasia Journal of Mathematics, Science and Technology Education, 15(2).

Hidayat, W., \& Sariningsih, R. (2018). Kemampuan Pemecahan Masalah Matematis dan Adversity Quotient Siswa SMP Melalui Pembelajaran Open Ended. JNPM (Jurnal Nasional Pendidikan Matematika), 2(1), 109. https://doi.org/10.33603/jnpm.v2i1.1027

Lee, C. J., \& Kim, C. M. (2017). A technological pedagogical content knowledge based instructional design model: a third version implementation study in a technology integration course. Educational Technology Research and Development, 65(6), 1627-1654. https://doi.org/10.1007/s11423-017-9544-z

Lin, Y., Zhou, Y., Wang, S., \& Wijaya, T. T. (2020). Lesson design of geometric sequences based on the 6-question cognitive theory. Journal On Education, 02(04), 313-322.

Mathematica, H. (1978). The Origins of Caucliy's Theory of The Derivative. Historia Mathematica, 5(1), 379-409.

Qin, L., Zhou, Y., \& Tanu, W. T. (2019). The Analysis of Mathematics Adversity Quotient of Left Behind Junior High School Students in Rural Areas. Open Journal of Social Sciences, 331342. https://doi.org/10.4236/jss.2019.710028

Rohaeti, E. E. (2010). Critical and Creative Mathematical Thinking of Junior High School Students. Educationist, IV(2), 99-106.

Sha, L. (2019). Practical Research on Integration of Information Technology and Kindergarten Music Teaching. Journal of Physics: Conference Series, 1345(4). https://doi.org/10.1088/17426596/1345/4/042028

Tan, S., Zou, L., Wijaya, T. T., Suci, N., \& Dewi, S. (2020). Improving student creative thinking ability with problem based learning approach using hawgent. Journal on Education, 02(04), 303-312.

Verlag, F. S., \& Leibnitiana, S. (2013). Fermat's Analysis of Extreme Values and Tangents. Studia Leibnitiana, 1, 20-41.

Wijaya, T. T., Dewi, N. S. S., Fauziah, I. R., \& Afrilianto, M. (2018). Analisis Kemampuan Pemahaman Matematis Siswa Kelas IX Pada Materi Bangun Ruang. UNION: Jurnal Ilmiah Pendidikan Matematika, 6(1), 19-28. https://doi.org/10.30738/.v6i1.2076

Wijaya, T. T., Purnama, A., \& Tanuwijaya, H. (2020). Pengembangan Media Pembelajaran Berdasarkan Konsep Tpack pada Materi Garis dan Sudut Menggunakan Hawgent Dynamic Mathematics Software. JPMI - Jurnal Pembelajaran Matematika Inovatif, 3(3), 205-214. https://doi.org/10.22460/ipmi.v1i3.205-214

Wijaya, T. T., Ying, Z., Cunhua, L., \& Zulfah. (2020). Using vba learning media to improve students' mathematical understanding ability. Journal On Education, 02(02), 245-254.

Yi, L., Ying, Z., \& Wijaya, T. T. (2019). The Trend of Mathematics Teaching Method Has Change From Fragments To Systematics. Journal Cendekia: Jurnal Pendidikan Matematika, 3(2), 471-480. https://doi.org/10.31004/cendekia.v3i2.137 